\section{Research plan to reduce health disparities in the United States of America ${ }^{1}$}

Key words: Equity, research, ethnic groups, United States of America.

\footnotetext{
1 Based on: United States of America, Department of Health and Human Services, National Institutes of Health. Strategic research plan to reduce and ultimately eliminate health disparities: fiscal years 2002-2006. Bethesda, Maryland: NIH; 2000. Available from: http://www.nih.gov/about/hd/strategicplan.pdf. Accessed 5 December 2000.
}

The health of persons living in the United States of America has generally improved in recent decades. Nevertheless, there are still noticeable differences between the burdens of illness and death experienced by the majority of the country's population and by such minorities as African-Americans, Hispanics, Native Americans, Alaska Natives, Asians, and Pacific Islanders. These minority groups suffer from a shorter life expectancy, as well as higher rates of cardiovascular disease, cancer, infant mortality, birth defects, asthma, diabetes, stroke, sexually transmitted diseases, and mental illness (see box, "The scope of health disparities in the United States").

Racial and ethnic minorities now make up some $28 \%$ of the population in the United States, but that figure is expected to be almost $40 \%$ in 2030 .

Various agencies of the Government of the United States are working to reduce these health disparities. One of them is the National Institutes of Health (NIH), which is one of the world's foremost medical research centers and is part of the United States Department of Health and Human Services. $\mathrm{NIH}$ is comprised of 25 separate institutes and centers that focus on particular illnesses and other major health concerns. Building on its earlier efforts, NIH recently issued a draft version of a fiveyear plan entitled "NIH Strategic Research Plan to Reduce and Ultimately Eliminate Health Disparities." The detailed document describes many of the specific health disparities in the United States, as well as the three major areas where NIH will focus its own efforts in reducing these disparities: research; research infrastructure; and public information and community outreach.

\section{RESEARCH RELATING TO HEALTH DISPARITIES}

The NIH plan outlines ongoing and future efforts to support and conduct research that is multifaceted and takes into consideration factors ranging from the molecular to the population level. Expanded and new research efforts will focus on three major concerns: understanding the development and progression of disease that contributes to health disparities; developing new or improved approaches for preventing, detecting, and diagnosing 
disease and disability; and finding better ways of treating disease and disability.

\section{Better understanding the development and progression of the diseases and disabilities that contribute to disparities}

Research on normal biological processes and how they malfunction in disease and disability can provide the foundation for investigations that lead to new methods for diagnosing, treating, and preventing disease and disability in different populations. This knowledge will be important for clarifying why rates and outcomes of illness differ among population groups.

To advance understanding of the development and progression of diseases that contribute to health disparities, $\mathrm{NIH}$ proposes pursuing a variety of approaches. These include studies of epidemiology and risk factors among diverse populations, the effects of environment and socioeconomic status on disease and health outcomes, differences in the initiation and progression of disease and disability, and the role of genetic variation in the causes and course of disease and disability.

Epidemiology and risk factors. Population studies can help uncover the underlying causes of disparities in health and can provide a framework for additional basic and applied research. The NIH strategic research plan proposes continuing or beginning studies of epidemiology and risk factors for various conditions, including stroke, cancer, cardiovascular disease, hepatitis $C$, drug abuse and addiction, sexually transmitted diseases, glaucoma, and youth violence.

In the area of cardiovascular disease, for example, the strategy proposes that NIH continue its support of a prospective review of the environmental and genetic factors affecting the disproportionate incidence of cardiovascular diseases in AfricanAmerican men and women. NIH will also expand its support for the Bogalusa Heart Study, which has been investigating a population of African-American and Caucasian persons and their cardiovascular disease risk factors for more than 25 years; the study will follow those individuals into middle age and beyond.

In the area of cancer surveillance, NIH will work with the National Center for Health Statistics (NCHS) of the Centers for Disease Control and Prevention $(C D C)$ to improve coordination of national cancer surveillance research and control programs. $\mathrm{NIH}, \mathrm{CDC}$, and NCHS will produce a multiyear plan for collaborative activities in the analysis and dissemination of a cancer-related health survey, of health survey methodology, and of techniques for improving the quality and availability of data to measure population-based health disparities. In addition, NIH will expand the Surveillance, Epidemiology, and End Results (SEER) Program to include populations that are currently underrepresented, including Hispanics, rural African-Americans, and American Indians. That expansion will strengthen the existing national infrastructure for surveillance research and will lead to improved understanding of health disparities in cancer outcomes among major ethnic populations.

With glaucoma, various studies in the United States have established race as a significant risk factor for primary open-angle glaucoma, and have confirmed substantially higher rates of the disease among African-Americans. To add to this knowledge, the NIH strategy advocates glaucoma studies with other minority populations, including Hispanics and Native Americans.

To help deal with youth violence the $\mathrm{NIH}$ Youth Violence Consortium will collaborate in efforts to understand the antecedents, social and neurobiological causes, and outcomes of violent youth behavior. NIH will also support another collaborative effort across racial and ethnic lines to study the short-term and long-term effects of domestic violence during pregnancy and the effects of domestic and community violence on children.

Effects of the environment and of socioeconomic status on disease and health outcomes. The ways in which poverty contributes to health disparities are still poorly understood, the NIH strategic plan points out. To help better understand the effects of social and physical environments on human health and disease, NIH will undertake a variety of efforts. For example, NIH will support research into the fetal antecedents of, and biomarkers for, differences in rates of hypertension, stroke, diabetes, and coronary heart disease. Other studies will work to identify how deficiencies in the uterus influence the developing fetus and contribute to future chronic disease, define normal fetal growth, and identify other biomarkers in minority and nonminority groups.

Differences in the initiation and progression of disease and disability. Other NIH work will focus on the mechanisms of disease and differences in the initiation and progression of disease and disability. For example, NIH will significantly expand 
its perinatal research in order to better understand the pathophysiological, social, and behavioral factors that lead to preterm births and low birthweight. These efforts will include work to clarify the causes of health disparities in preterm births and in adverse neonatal outcomes arising from infectious/inflammatory disease processes, as well as to identify genetic factors that predispose women and their infants to preterm births and low birth weight, especially among racial and ethnic populations.

Genetic variation in the causes and course of disease and disability. Understanding variations in gene expression in diverse populations could be an important step towards reducing health disparities. Nevertheless, there is little population-based data on genetic and epidemiological factors that play a role in the disproportionate rates and burdens of such diseases as cancer and diabetes among minorities. In response, NIH has launched initiatives to collect population-based data that will help identify genes underlying susceptibility to common diseases in minority populations, and to understand the function of these genes and their interaction with environmental factors.

In the area of diabetes, for instance, NIH will promote research on the causes of the disease in minority populations, to help determine the underlying physiologic, metabolic, genetic, psychosocial, and behavioral factors that lead to racial and ethnic differences in diabetes incidence.

Other programs supported by NIH will continue examining the genetic basis of hypertension, with one subproject focusing on African-Americans. Another program involves a collaborative network to identify genes associated with high blood pressure; 61 percent of the participants in that program are African-American.

\section{Improved approaches to preventing and delaying the onset or progression of diseases and disabilities}

Many different disciplines can contribute to a better understanding of ways to prevent, delay, and halt disease. With obesity, for example, NIH supports a range of research studies that focus on the prevention of this condition among minority populations. One study seeks to determine if racial disparity in obesity among pubescent girls results from differences in diet and physical activity or from socioeconomic or other environmental factors, and if these distinctions could lead to racial differ-

\section{The scope of health disparities in the United States}

There are many illnesses and other health conditions for which there are disparities between the majority and minority populations in the United States, according to the NIH strategic research plan. The data below illustrate the magnitude and breadth of some of these disparities.

Infant mortality. While there was a $16 \%$ overall decline in the rate of infant mortality in the United States during the 1990s, the infant mortality rate remains twice as high among African-Americans as compared to Caucasians, even when controlling for socioeconomic factors. Native American and Alaska Native infants also have a death rate almost twice that of Caucasians.

Maternal mortality and morbidity. Since the $1950 \mathrm{~s}$ maternal mortality rates in the United States have decreased dramatically. However, as compared to Caucasians, the mortality rate remains four times higher among African-American mothers and 1.6 times higher for other racial groups. Many of these deaths are preventable. A number of factors influence maternal morbidity in minority populations. For example, African-American women develop uterine fibroids up to two to three times more frequently than do Caucasian women.

Poverty and child health. In 1996, African-American and Hispanic children were four times more likely to be living in poverty than were Caucasian children. These disadvantaged children experience a disproportionate array of health problems, including high rates of low birth weight, contagious diseases, obesity, exposure to hazardous substances, and childhood injury and death. Poorer children are also at greater risk for developmental and learning delays, as well as social, emotional, and behavioral problems. 
Heart disease. Despite impressive progress in reducing cardiovascular mortality over the past several decades, there still exists a disproportionate burden of death and disability from cardiovascular disease in minority and low-income populations. For example, the prevalence of coronary heart disease in African-Americans has increased steadily since the early 1970s, with coronary heart disease mortality $40 \%$ higher for African-Americans than for Caucasians. Similarly, fewer African-Americans survive severe cardiomyopathy as compared to Caucasians, a difference attributed to both biological and socioeconomic factors.

Stroke. Stroke is the third leading cause of death in the United States, killing approximately 150000 Americans every year. The incidence of stroke is disproportionately high in African-Americans, with a mortality rate that is nearly $80 \%$ higher than in Caucasians.

Sickle cell anemia. In the United States sickle cell anemia primarily affects African-Americans, with one in 12 of them carrying the sickle cell trait and with some 72000 of them having the disease. It is also the most important cause of stroke among African-American children.

Cancer. Many minority groups in the United States suffer disproportionately from cancer, with disparities in both mortality and incidence rates. AfricanAmericans have both a higher overall incidence and a higher death rate than any other racial or ethnic group. The death rate from stomach cancer is substantially higher among Asian and Pacific Islanders, including Native Hawaiians, than among other populations. Vietnamese women in the United States have a cervical cancer incidence rate that is five times greater than Caucasian women. African-American and Hispanic women have higher cervical cancer death rates than do other women in the United States.

Type 2 diabetes. Type 2 diabetes is disproportionately manifested in minority groups. The prevalence of diabetes in African-Americans is nearly ences in stroke, high blood pressure, and blood lipid levels. The study has been extended to track the participants into early adulthood, when there seem to be obesity-related changes in stroke and cardiovascular risk factors. Another effort among African-American girls at high risk for obesity is testing the effectiveness of various weight-control interventions during the critical transition from prepuberty to puberty. For years NIH has carried out clinical and epidemiological research on obesity and diabetes among the Pima Indians of the state of Arizona. Type 2 diabetes is extremely common among that tribe. To investigate the biological and behavioral causes of that, NIH has conducted genetic studies, intervention trials, and studies of prevention and treatment.

\section{Better approaches for treating diseases and disabilities}

The aim of much NIH research is to develop new and improved therapeutics. In part, such development depends on a strong foundation of understanding disease mechanisms and how normal and abnormal biological functions may vary in different populations. In addition, health services research is needed to study the ultimate effect that any new approach has on the burden of a disease, on both the individual and society.

One of the areas where this is true is cancer survivorship. According to the NIH research plan, research is needed on the ethnic and cultural factors that affect cancer survivorship. NIH will support studies on the impact of cultural, socioeconomic, and institutional factors on the quality and length of cancer survivorship in underserved communities. Developmental research will elucidate the similarities and differences in the survivorship experience across ethnic minority and medically underserved groups. A future effort will expand psychosocial and behavioral intervention research among minority and underserved cancer survivors and their families, with the potential of improving the quality and length of survival.

With tuberculosis, NIH is helping to develop or evaluate new assays, markers, prevention approaches, and therapies, including a new drug that is taken less often, which may address a major compliance problem among minorities. NIH is also supporting epidemiological studies on genetic and environmental factors that contribute to tuberculosis.

Two NIH initiatives are assessing diet in the control of hypertension among minorities. One of the initiatives, in which $50 \%$ of the participants are African-American, assesses the effects of three lev- 
els of sodium intake and two diets. One of the diets is a reference diet, and the other is the so-called DASH diet, which is low in fat and high in fruits and vegetables. The other initiative is looking at the effect that the DASH diet has on blood pressure when that diet is combined with such lifestyle interventions as reduced salt use, increased exercise, moderate alcohol consumption, and weight loss; $41 \%$ of the participants in that research are AfricanAmerican.

Other NIH research is looking at HIV infection and metabolic change. Some therapies for HIV have produced metabolic complications, including peripheral weight loss, possible bone loss, atherogenic lipid profiles, and diabetes. Since Hispanics and African-Americans are disproportionately affected by AIDS and also at greater risk of diabetes and cardiovascular disease, these metabolic complications are particularly serious for them. To investigate the problem NIH has funded a nationwide, multicenter study that should provide insights into the cause and potential disparity in metabolic abnormalities associated with HIV, and provide the foundation for targeted studies on etiology and treatment in minority groups.

\section{RESEARCH INFRASTRUCTURE}

The second major component of the NIH plan on health disparities concerns the infrastructure of biomedical research, including biomedical researchers and personnel, the means and resources for supporting and training them, and recruiting and retaining biomedical investigators who are from diverse backgrounds. Another aspect of the infrastructure issue is research facilities, equipment, and supportive services.

\section{Support for research training and career development}

$\mathrm{NIH}$ has numerous initiatives to promote training and career development that could lead to reduced health disparities. Among these are training programs specifically designed to provide support to graduate and postdoctoral students from minority populations and to recruit these professionals into research at earlier career levels. For example, $\mathrm{NIH}$ will expand existing programs that support minority investigators with their doctoral dissertations, as well as with travel awards to allow students and faculty to attend conferences and training sessions on health disparities. NIH will extend its efforts to strengthen the competitiveness of researchers from
$70 \%$ higher than in Caucasians. Native Americans, Hispanics, African-Americans, and some Asian Americans and Pacific Islanders are at particularly high risk of developing type 2 diabetes. Most strikingly, diabetes prevalence rates among American Indians are two to five times those of Caucasians, with the Pima tribe of Arizona experiencing one of the highest rates of diabetes in the world.

HIV and AIDS. Of the new AIDS cases in the United States in 1998 that were reported to the Centers for Disease Control and Prevention, the rate per 100000 population was 81.9 among AfricanAmericans, 34.7 among Hispanics, 8.4 among Caucasians, 9.4 among Native Americans and Alaska Natives, and 4.1 among Asians and Pacific Islanders. HIV incidence is growing at a greater rate in women than in men, particularly among minority women. The proportion of new AIDS cases among women more than tripled from 1985 to 1998 , from $7 \%$ to $23 \%$. By the end of 1998 in the United States, of the women infected with HIV, $57 \%$ of them were African-American and $20 \%$ were Hispanic.

Sexually transmitted diseases. The current epidemic of sexually transmitted diseases (STDs) in the United States disproportionately affects minorities. For example, in 1997 the rate of gonorrhea was 31 times greater among African-Americans than Caucasians, and 3 times greater among Hispanics. This disparity is particularly significant in light of recent studies indicating that STDs can significantly increase the risk of HIV transmission.

Tuberculosis. In the United States tuberculosis has reemerged as a serious public health problem, and one that affects minorities disproportionately. For example, in 1998, $75 \%$ of active tuberculosis cases were reported in racial and ethnic minorities. This was largely due to a combination of urban poverty, overcrowded living conditions, HIV infection, and inadequate treatment and/or compliance with tuberculosis therapy. Although constituting only $11 \%$ of the total population in 1996, Hispanics accounted for $20 \%$ of the new cases of tuberculosis. 
minority institutions by expanding its innovative workshops on grant writing and evaluation.

$\mathrm{NIH}$ will initiate training programs for health disparities in mental health, for both undergraduate and graduate students. Part of this effort will include predoctoral fellowship training programs that combine medical school and predoctoral support for students in areas that contribute to understanding health disparities in mental health.

Another area of NIH work will be international research, such as by expanding research in countries whose populations share similar ethnic backgrounds as minority populations facing health disparities in the United States.

Through genomic and genetic research, $\mathrm{NIH}$ will help expand efforts to understand the biological origins of health disparities. One program will recruit minority postdoctoral scientists to work with a mentor in a specialized field of genetic research. Another program will provide courses in the latest genomic developments, genetic technology, medical genetics, and gene therapy for faculty at minority institutions.

For many years NIH has conducted an intramural program of research looking at the extremely high incidence and prevalence of type 2 diabetes mellitus and obesity among the Pima Indians of Arizona. This population is currently participating in the Diabetes Prevention Program (DPP) clinical trial. In a major new initiative, the DPP will be used as a vehicle to train American Indian and Native Hawaiian investigators so they can continue similar investigations in their respective communities.

NIH will continue its work with Howard University, in Washington, D.C., to strengthen ongoing studies looking at the genetic factors associated with diabetes mellitus and prostate cancer among African-Americans. These studies form the nucleus of an evolving National Human Genome Center at that university. This center will not only strengthen the research infrastructure of Howard University, but also provide cutting-edge research and training opportunities for minority researchers.

At universities that have large numbers of minority students and researchers, NIH will initiate research programs on effective ways to avoid violence and unintentional injury and on methods to strengthen parenting within the community.

\section{Support for extramural and intramural institutional resources}

In addition to encouraging the training and career development of individual students and researchers, NIH also supports the research infra- structure needs of institutions, by helping build research programs, develop laboratories, and create curricula to meet special needs, including at institutions with large numbers of minority students.

That infrastructure support is taking a variety of forms. One is the building of the capacity of minority institutions to participate in advanced computing technologies. Much of this effort is focused on the Internet, such as a project to improve Internet connectivity and access to health information services in Native American and Alaskan Native communities. Another program is working to strengthen telecommunications linkages among the member institutions of the Minority Health Professions Foundation, which will help bring information resources to underserved populations in the United States and allow minority colleges and universities to build telemedicine links with each other.

$\mathrm{NIH}$ will also work with community institutions to create a community-based research infrastructure to address the health needs of minority groups in the United States, such as through basic research and multidisciplinary interventions addressing poor birth outcomes. These efforts will provide opportunities for community-based research training and also help disseminate researchbased information to the community.

Another aspect of support to institutions concerns the review process for $\mathrm{NIH}$ grants relating to health disparities. NIH is working to ensure appropriate levels of representation by minority scientists and experts on the scientific review groups, or "study sections," that help assess requests for NIH funding for research and training.

\section{PUBLIC INFORMATION AND COMMUNITY OUTREACH}

Communicating research findings and health messages to all segments of society can be an important means for NIH to help eliminate health disparities. The general public, patients, health care providers, the media, scientists, and policymakers need to be aware of medical research findings that can be applied to improving health. NIH must continue its efforts to translate highly technical research advances into clear, culturally relevant explanations of the steps that individuals can take to improve their health. In this public information effort, NIH has three major objectives: developing research-based information resources, disseminating research-based information that will increase public awareness, and transferring knowledge to health care providers 


\section{Research-based information resources}

One aspect of the NIH effort to develop research-based information resources is the creation of materials in languages other than English, particularly Spanish. Through the NIH Hispanic Communications Initiative, for example, curriculum supplements are being translated into Spanish for use in adult education programs and in schools with large numbers of minority students. Another project, to improve cardiovascular health among Hispanics, has developed informational materials for consumers, health care workers, and others. Other NIH efforts will produce materials in other foreign languages, including the Navajo Indian language.

One area where NIH is seeking to better disseminate its research findings is drug abuse and addiction. NIH will sponsor a national conference on drug abuse and addiction in diverse communities, and the information from that meeting will be used to develop such materials as a printed guide and an Internet Web site.

Another way for NIH to better develop and disseminate its research-based information resources is through broader recruitment of minorities into clinical trials. With mental health clinical trials, for example, NIH will place advertisements in minority publications and other publications with large numbers of minority readers, as well as develop recruitment kits, fact sheets, and videotapes to educate prospective participants.

Another NIH research effort is entitled the Health Information National Trends Survey, or HINTS. This biennial longitudinal study will investigate Americans' access to and use of health information. In the area of cancer, the survey will oversample minorities in order to better identify how they seek information about that disease.

$\mathrm{NIH}$ is also disseminating information to minorities and others through various information clearinghouses that it supports, and NIH will work to better publicize these clearinghouses with minority communities.

\section{Research-based information to increase public awareness}

$\mathrm{NIH}$ will continue to use a variety of communications strategies and mechanisms to provide the public, including members of minority populations, with research-based information on a variety of health issues. One example is the National Diabetes Education Program, which involves a collaborative effort by the $\mathrm{NIH}$, the $\mathrm{CDC}$, and some 150 public and private partner organizations. That program will expand its work in order to increase awareness of type 2 diabetes and how to control it, among minorities, health care providers, the health insurance sector, and policymakers.

On the issues of toxicology, environmental health, and hazardous waste, NIH will expand its activities with colleges and universities that traditionally have had large numbers of African-American students, as well as with minority and disadvantaged communities.

The NIH will expand its campaign to increase public awareness of hearing loss caused by noise, through efforts that include a special outreach to Hispanic seasonal workers and others who work in environments with dangerous noise levels.

In another effort involving the Internet, the $\mathrm{NIH}$ will support a project to determine whether giving minority children and adolescents who have type 1 diabetes better access to electronic information resources will help them manage their diabetes and avoid costly and debilitating complications. Also with diabetes, NIH will provide technical consultation on smart-card technology to improve both diabetes care and adherence to preventive measures in type 2 diabetic Latinos and African-Americans living in low-income sections of Los Angeles County.

Through the Asian and Pacific Islander Project, NIH is developing a community awareness campaign to promote heart-healthy behaviors. Planned activities include developing culturally appropriate products and setting up a network of community partners that will include local community groups, churches, clinics, and social service agencies.

To help deal with a high incidence of drunk driving among Hispanic men, NIH is working with other Government agencies and private organizations to research and develop a public awareness program aimed at reducing that behavior.

\section{Knowledge for health care providers}

Educating health care providers about research findings and disseminating science-based health messages is a critical link in NIH's efforts to reduce health disparities. For example, NIH will establish a National Kidney Diseases Education Program to help reduce the burdens of end-stage renal disease on minorities and to work with patients and professionals to identify the most effective screening and disease interventions, with appropriate messages to specific audiences. Given the high incidence of glaucoma, diabetic retinopathy, and visual 
impairment in minority populations, the NIH's National Eye Health Education Program is working to tailor informational and educational materials to meet the needs among those target audiences.

In addition to this trans-NIH research agenda, each of the institutes and centers within NIH has developed its own specific, detailed strategic plan for reducing health disparities in the United States. These plans can be viewed on the NIH Internet site at: http://healthdisparities.nih.gov/working/ institutes.html

\section{SINOPSIS}

\section{Plan de investigación para reducir las disparidades de salud en los Estados Unidos de América}

La salud de los habitantes de los Estados Unidos de América (EE.UU.) ha mejorado en las últimas décadas, pero, a pesar de ello, sigue habiendo diferencias notables entre la carga de enfermedad y la mortalidad de la mayoría de la población del país y de minorías tales como los afroamericanos, los hispanos, los indios norteamericanos, los indígenas de Alaska, los asiáticos o los oriundos de las islas del Pacífico. Estas minorías raciales y étnicas, que en la actualidad representan cerca del $28 \%$ de la población de los EE.UU., tienen menor esperanza de vida y presentan mayores tasas de enfermedad cardiovascular, cáncer, mortalidad infantil, malformaciones congénitas, asma, diabetes, accidentes vasculares cerebrales, enfermedades de transmisión sexual y enfermedades mentales. Entre los organismos gubernamentales de los EE.UU. que están trabajando para reducir estas disparidades de salud se encuentran los Institutos Nacionales de la Salud (National Institutes of Health: NIH). Basándose en sus propios esfuerzos anteriores, los NIH han publicado recientemente un borrador de un plan quinquenal denominado "Plan estratégico de investigación del NIH para reducir y eliminar las disparidades de salud". El documento describe las tres áreas principales en las que los NIH centrarán sus esfuerzos para reducir dichas disparidades: investigación, infraestructura de investigación, e información pública y expansión de los servicios a la comunidad.

Making a Difference: Social Inequality in Health: international conference

$\begin{array}{ll}\text { Dates: } & \text { 14-16 May } 2001 \\ \text { Location: } & \text { Clarion Hotel Oslo Airport, } \\ & \text { Gardermoen, Norway }\end{array}$

A conference on social inequality in health will be held in Oslo, Norway, to focus on such issues as whether the gap in social inequality in health is widening, and the effect that past and present health policies have had on inequality in health.

The program will be mainly in English, with a few talks or panels in Scandinavian languages.

The conference is intended for researchers and practitioners in the public health field, physicians and other health professionals, sociologists, social workers, epidemiologists, and persons working in the areas of public information and prevention.

The conference is a collaborative effort of the National Institute of Public Health of Norway, the Norwegian Association for Public Health, and the Norwegian Society for Public Health.

Information:

Web site: National Institute of Public Health of Norway, at: http://www.folkehelsa.no/hvaskjer/makadiff.html

E-mail: Heidi Lyshol, National Institute of Public Health of Norway, heidi.lyshol@folkehelsa.no 